\title{
FAMILY AND THE PROCESS OF COMMUNICATIVE DEVELOPMENT IN CHILDREN WITH ASD (AUTISM SPECTRUM DISORDER
}

\author{
Fernanda Dreux Miranda Fernandes ${ }^{a}$; Cibelle Albuquerque de la Higuera Amato ${ }^{b}$ \\ Daniela Regina Molini-Avejonas ${ }^{c}$; Carla Cardoso ${ }^{d}$
}

\section{OBJECTIVE}

The purpose of tis study was to identify the anxieties and desires of a group of 15 parents/caregivers of children with Autism Spectrum Disorders

The study was approved by the institutions ethic's committee and all parents signed the consent form. The participants of this research were parents and / or caregivers of children attending outpatient clinics participating in this research who were in speech therapy for a period of more than 6 months and less than 24 months. To ensure the ethics of the research procedure, all parents and / or caregivers of children attending these outpatient clinics were invited, but only parents and / or caregivers who met the inclusion requirements were included in the research. Data collection was performed at the Speech-Language Pathology Clinic of the Bahia State University. Data collection and analysis procedures were initiated following the relevant ethical processes: Opinion of the Ethics Committee of the University of São Paulo School of Medicine (CAAE: 25403113.2.0000.0057 / Number: 2.178.700) and signature of the Consent Form - Information by those responsible. Health promotion actions were performed for parents and / or caregivers. All parents and / or caregivers of children in attendance were invited to attend weekly workshops for a period of 6 months and an estimated duration of one hour. These meetings were held at the time the children were undergoing speech therapy. The actions were performed based on the participants' own demand. These meetings were held based on the methodology of the Focus Groups (PENTEADO et al, 2006) which provides for the continuous process of information and knowledge exchange based on the prior knowledge of the target audience, in this case the parents and / or caregivers, considering the participatory character. collective and dynamic. Membership in these workshops was voluntary. All actions were recorded in video and audio for further analysis; For data analysis, the qualitative interpretation of data proposed by Minayo (1992) was performed. As an additional tool, Word Cloud analysis was used. This tool is for online use.
Results suggest that each family deals with their child's communicative disorders according to their own experiences, values and hopes. The most frequent concern was the absence of speech, as the lack of verbal communication is stressful in everyday routines.

Fig. 01- Word Cloud referring to the theme during the first meeting, where speech was the main concern of the families (CARDOSO, 2019)

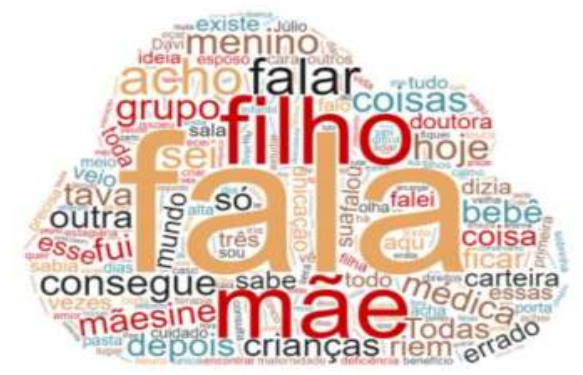

Therefore, we consider that language alteration permeates the scope of this individual and especially with regard to the family environment and this mainly due to the place of valorization of speech.

Another issue refers to the difficulties in obtaining the diagnostic and the lack of information regarding the disorder. These results emphasize the important of supportive network comprised of caregivers and professionals that can share information, experiences and concerns or simply mutual support

Fig. 02- Word cloud referring to the second meeting, where the diagnostic process, reactions and support were the main concerns (CARDOSO, 2019)

\section{CONCLUSION}

\begin{abstract}
Communication disorders are still an area where most parents express need for more information and social, cultural and educational contexts and backgrounds are essential to any supportive intervention. It is of utmost importance to think about the child with ASD considering their language and overall development, but also the social context and the expanded family as the origin of the meaning of symbolic exchanges.
\end{abstract}

